\title{
Infrastructures of Care: Opening up "Home" as Commons in a Hot City
}

\author{
Abby Mellick Lopes' \\ School of Humanities and Communication Arts, Western Sydney \\ University, Australia \\ Stephen Healy \\ Institute for Culture and Society, Western Sydney University, Australia \\ Emma Power \\ Institute for Culture and Society, Western Sydney University, Australia \\ Louise Crabtree \\ Institute for Culture and Society, Western Sydney University, Australia \\ Katherine Gibson \\ Institute for Culture and Society, Western Sydney University, Australia
}

\section{Abstract}

What does it mean to be at home in a hot city? One response is to shut our doors and close ourselves in a cocoon of air-conditioned thermal comfort. As the climate warms, indoor environments facilitated by technical infrastructures of cooling are fast becoming the condition around which urban life is shaped. The price we pay for this response is high: our bodies have become sedentary, patterns of consumption individualized, and spaces of comfortable mobility and sociality in the city, termed in this paper as "infrastructures of care," have declined. Drawing on the findings of a transdisciplinary pilot study titled Cooling the Commons, this paper proposes that the production of the home as an enclosed and private space needs to be rethought as an infrastructure that potentially undermines more social, convivial, and environmentally sensitive responses to a warming world. The paper asks, what role might design now play in developing alternative infrastructures of care that start with the idea of "home" as a distributed proposition?

Keywords: commons, home, infrastructures of care, sustainable design, urban cooling

1 Corresponding author: a.lopes@westernsydney.edu.au. 


\section{Introduction}

Suburban Western Sydney in Australia is undergoing rapid population growth and urban densification, with a projected construction of 180,000-plus dwellings planned in the next 15 to 20 years (Greater Sydney Commission, 2018). Once covered in woodlands and bushy waterways, this region of the Sydney Basin is rapidly disappearing under asphalt and concrete, with the consequent loss of shade-giving tree canopy (Jacobs et al., 2014). Distant from coastal sea breezes, it is experiencing increasingly hostile and record-breaking summer temperatures that will be further exacerbated by urban development. Particular "hot spots" with land surface temperatures of $50^{\circ} \mathrm{C}\left(122^{\circ} \mathrm{F}\right)$ and beyond have been recorded, and these often coincide with low socioeconomic status areas (Amati et al., 2017; Australian Bureau of Statistics [ABS], 2018a; Penrith City Council, 2015). ${ }^{2}$ As rising urban heat increasingly presents disruptive challenges to being "at home" in the world, this paper explores how these challenges are also opportunities to provoke us to design home environments differently.

New houses in Western Sydney, as all around Australia, are being designed around air-conditioning to deliver thermal comfort. Driving the move indoors, airconditioning and its broad implications are a significant contributing factor to the rise of indoor ecosystems explored in this special issue. In a national survey of human activity patterns in the United States (US), Klepeis et al. (2001) found that people are spending around $90 \%$ of their time inside enclosed buildings or vehicles. Yet, the structuring-in of air-conditioning as the primary response to urban heat is having multiple detrimental effects on urban lifeworlds - that is, the world as lived. Increased demand for energy derived from fossil fuels is contributing significantly to global warming, people are being forced indoors into increasingly individuated social spaces, and household energy bills are skyrocketing. ${ }^{3}$ With this move, the perceived need for publicly accessible infrastructures that facilitate a slower, more pedestrian-oriented city is being diminished. For those economically disadvantaged groups living in the Western Sydney region who have less capacity to access or pay for air-conditioning, livability is being increasingly compromised.

During the summer of 2016, a transdisciplinary team of researchers from the disciplines of design, geography, economics, landscape architecture, and cultural studies spoke to a group of 14 active seniors, 10 Aboriginal mothers with preschoolaged children, and a group of seven elderly carers living in the hot spots of Penrith

\footnotetext{
2 This correlation between distributions of income and tree canopy cover in urban centers is a global issue. For example, see Schwarz et al.'s (2015) study examining the burden of environmental hazard carried by low-income and minority populations across seven US cities. The authors point out some interesting disincentives for urban trees including a resistance to the "gentrification" that comes with tree cover, as it also brings rising rents.

3 See Nicholls et al. (2017) for a detailed qualitative study of the effect of electricity pricing and messaging on low-income households in Australia.
} 
City in Western Sydney. The particular heat vulnerability of the elderly, the very young, and the economically disadvantaged is well established in the literature (Loughnan et al., 2013). However, we wanted to look beyond the assumption of vulnerability to explore what people living in these "hot spots" do during summer to cope with the heat. Our methods included observational site analyses and group interviews aided by visual prompts, including thermographic imagery. We sought to capture not only what people could say about what they do, but also the less conscious or "tacit" dimensions of practical activity, as "we know more than we can tell" (Polanyi, 2009, p. 18). The data produced helped us understand how features of the environment influence people's efforts to keep cool inside their homes and outside in public spaces. Thematic analysis also revealed details about everyday practices as people attempted to work around these conditions, and the aspirations people held for the future of their city.

The accounts gathered in the preliminary study, titled Cooling the Commons, complements the now significant body of quantitative literature on the effects of urban heat (Hughes et al., 2016; Lewis et al., 2017; Mellick Lopes et al., 2016) and studies that identify key design considerations to ameliorate these consequences (Osmond \& Sharifi, 2017). This study contributes key insights into the social, cultural, and material contexts that inhibit or support cooling strategies, or that make space for individual agency (Bell et al., 2014).

The research findings point to the ways that individual and community capacity to cope with urban heat is constrained or enabled by housing design, housing tenure arrangements, the design of public spaces, networks, and everyday material circumstances. Lives are lived within the enclosed confines and open avenues of a set of infrastructural relationships that circulate in, around, and beyond the home. We can think of a particular set of infrastructural relationships as those that achieve coolth: the sensation of feeling cool in a heated atmosphere. In this paper it is argued that technical infrastructures of urban cooling that privilege air-conditioning are threatening the provision of other infrastructures that afford experiences of coolth, notably shade, shelter, public water, and places to comfortably rest and wait while moving about the city. Likewise, there needs to be a concerted effort to intervene in this process for the future well-being of inhabitants of a hot city.

The paper proceeds with a critical discussion of how air-conditioning, as a technical cooling infrastructure, has shaped urban lifeworlds. "Infrastructures of care" are next introduced as social and technical infrastructures that can be made and shared by communities in their efforts to keep cool, followed by a discussion of how this analysis helps to generate a provisional set of considerations for the design of future infrastructure of care. 


\section{Cool Enclosures}

Infrastructure is not identical to system or structure, as we currently see them, because infrastructure is defined by the movement or patterning of social form. It is the living mediation of what organizes life: the lifeworld of structure. Roads, bridges, schools, food chains, finance systems, prisons, families, districts, norms [are] all ... systems that link ongoing proximity to being in a world-sustaining relation. (Berlant, 2016, p. 393)

In considering Lauren Berlant's (2016) reframing of infrastructure, not as a technical system or built structure but as a movement or patterning of social form, we can view the history of climate control over the course of the twentieth and twentyfirst century as significantly changing the organization of urban life in ways we must now challenge. The earliest efforts in creating climate-controlled environments were, according to Stephen Healy (2008), ${ }^{4}$ not in the house but in the context of temperature-sensitive manufacturing-from textiles to chocolate manufacture. In the early twentieth century there was a lively debate in the domain of public health that pitted approaches emphasizing the circulation of "fresh air" over the use of climate-control technologies that heated or cooled recirculated air. Initially, "fresh air" champions won the public health argument in the context of public buildings, but the advocates of climate control won the day through an appeal to a scientific understanding focused:

upon the quantitative study of human comfort (after an earlier focus upon a chemical theory of air had been disavowed). Building upon earlier work, the laboratory published the "Comfort Chart" that "graph[ed] ... the combinations of temperature and humidity at which most people felt comfortable." (Healy, 2008, p. 314)

Thermal comfort became an engineered condition, subject to what Shove (2003) called the "ratchet effect," by which imperceptible changes in designed conditions became the norm, constraining the possibility of retraction or backward movement. A working universal standard for the human body to achieve thermal comfort was set at around $22^{\circ} \mathrm{C}\left(72^{\circ} \mathrm{F}\right)$, regardless of the temperature outside (Shove, 2003, p. 26).

Healy (2008) charted how the concept of climate control spreads from industrial sites, to climate-controlled movie theaters, and shopping centers-all of which are sites of collective mingling. Eventually, climate control spread in the form of small air-conditioning units, to family homes, and then to automobiles. ${ }^{5}$

4 We note that this Stephen Healy is a history of science scholar based in Australia who shares a name with one of the authors of this paper.

5 Dolores Hayden (2002) documented a similar trajectory with collectively used appliances, such as dishwashing machines and vacuum cleaners used in hotels and rooming houses, migrating to individual households in miniaturized form. As a template, climate control anticipates the "smart home" Sofia (Sofoulis, 2000) presciently described nearly two decades ago as an environment that caters to (the largely male) fantasy of a command-andcontrol home, separated from the outside world, silently and efficiently shaping conventions and practices of comfort (Shove, 2003). 
The demand for air-conditioning also normalized over time, fundamentally informing the design of everyday urban life. Today, many urban dwellers' lives, work practices, and styles of dress, among other factors, are designed in anticipation of the $22^{\circ} \mathrm{C}\left(72^{\circ} \mathrm{F}\right)$ working temperature. Further, many indoor environments, from the home, to the office block, to the shopping (and data) center, and car, would be uninhabitable or grind to a halt without it.

Air-conditioned comfort is increasingly a feature of the built environment globally. Like the car industry in the last century, thermal comfort delivered through air-conditioning has become a primary signal of urbanization and rising affluence, and, therefore, of a modern, functioning economy (Davis \& Gertler, 2015). The emerging middle classes in China, India, Indonesia, and South America now constitute the largest market for air-conditioning. As reported by the Lawrence Berkeley Lab, the world is set to install 700 million new air-conditioners by 2030, and 1.6 billion by 2050, mostly in developing countries with hot climates (De la Rue du Can et al., 2015).

Yet, while the desire for thermal comfort is understandable in hot cities, the structuring-in of air-conditioning is exacerbating global warming. In addition to energy consumed in use, there are the potent emissions from the HFC refrigerants used in air-conditioners, as well as the effect of peak load, which severely stresses urban energy grids and leaves communities vulnerable to possible breakdown (De la Rue du Can et al., 2015). It is also more energy intensive to cool rather than to heat air, and air-conditioning (and refrigeration) produce and release heat back into the environment, exacerbating the urban heat island effect.

At the level of bodily experience, the "thermal monotony" created by air-conditioning means that humans lose the capacity to acclimatize to temperature variations in the greater environment (Healy, 2008). The key issue here is "the manner in which technologies fuse prosthetically with humans" (Tonkinwise, 2009, p. 33). Air-conditioning technologies make a human body that is different, physiologically, to one that would exist without it, one that appears to be less capable of responding to thermal variability, and that is engineered into forgetting this capacity. The body produced by indoor, climate-controlled environments is more sedentary and passive (Sofia [Sofoulis], 2000), as well as more vulnerable to environmental diseases such as asthma. Here we find an ironic confirmation of Annemarie Mol's (1999, 2002, 2008) assertion of the body's multiple ontologies - a progressive winnowing of what the human body can be by technologies that foreclose on other possibilities. In reality, the commitment to air-conditioning does not ensure "steady-state" thermal comfort. Notably, SafeWork NSW (n.d.), the state government workplace health and safety regulator, reported that "problems with air-conditioning are very common" (para. 7), as the experience of its adequacy changes according to dynamics of human movement and people's different tolerances to temperature. 
The delegation of active control to the built environment also modifies forms of sociality. During hot weather it encloses people in houses, cut off from others. For the body so acclimatized, the presence or absence of air-conditioning becomes a decisive factor influencing livability in a city, determining where you go, what you do, and with whom.

The conversations in Western Sydney afforded graphic insights into this infrastructure of cool enclosure that has been created by privileging built environment "solutions" to urban heat. Participants in the Cooling the Commons pilot found themselves increasingly restricted to indoor environments. For example, the group of carers described being completely reliant on air-conditioning and was largely confined to their homes during hot days due to the difficulties of getting around comfortably. An enduring image was one described by an elderly carer who was totally reliant on air-conditioning to transport their adult child between home and the community center. The carer explained that they routinely experienced being stuck at traffic lights in their car, and even with the air-conditioning on full bore still suffered the threat to their charge of potential heatstroke. Another common experience was the need to get back into a car that had been baking in the sun all day, and the problem of finding shade under which to wait while air-conditioning made the environment in cars more habitable.

In particularly hostile hot spots, many residents did not have access to airconditioning at all, and were coping with already excessive outside temperatures and internal environments that intensified the heat. These residents were further disempowered, as they did not have the capacity to modify their home environments for cooling due to poor design (e.g., lack of insulation and the use of cheap sliding rather than lockable sash windows, which limit the easy and secure circulation of air), or because they were renting or in social housing. ${ }^{6}$

A group of Aboriginal mothers living in poorly designed public housing were one group facing excessive and destabilizing indoor heat. The director of the local neighborhood center explained that the upper levels of their homes become uninhabitable in summer, leaving people needing to crowd in downstairs and take up residence in the neighborhood center during the day. Some mothers who took part in the Cooling the Commons study explained that their main option for managing heat was to remain completely still. Their children in childcare were not allowed to play outdoors after midmorning due to the lack of shade, and rather than ride their bikes, school-aged children came home straight after school to, in their words, "just chill." These ongoing issues are exacerbated by the lack of public transport infrastructure to enable people to easily get to cooling refuges such as a local public swimming pool.

6 The particular vulnerability of renters to urban heat was also found in Nicholls et al.'s (2017) study. 
Interestingly, the senior participants were highly critical of the "thermal indulgence" (Strengers \& Maller, 2017, p. 35) of younger generations, arguing they had learned to rely too heavily for their comfort on air-conditioning. The idea that thermal comfort was something you needed to take responsibility for and manage was strong in this group. Evidenced by one participant, seniors were very aware of the costs associated with fans and air-conditioning, and this energy-aware dwelling was a source of pride:

I have rules ... it has to be at least 30 degrees [ $86^{\circ} \mathrm{F}$; before I turn the air on]—usually my body can tell me. The other day it was 34 degrees $\left[93^{\circ} \mathrm{F}\right]$ before I turned it on ... as soon as it starts to cool down, we turn it off. (Participant, seniors group)

While this may be perceived as evidence of detrimental "thermal rationing" (Nicholls et al., 2017), these comments also point to different generational experiences and a loss of cooling know-how. They reflect a trajectory of cool enclosure that an infrastructure of built-environment climate control has charted.

Here, the term "enclosure" is used purposefully to connect with the long tradition of concern for enclosure of the commons. This does not refer to the process of legal exclusion and displacement of the English peasantry from the commons pasture, to make room for private property. This instance of enclosure radically reshaped the lifeworld of whole populations, confining their movements, cutting off options for survival, and proscribing new exploitative livelihoods within urban hells. The enclosure of urban life in individuated air-conditioned households with expensive energy bills is certainly not of the same order, but it does constitute a remaking of the built environment and reshaping of lifeworlds. Technical infrastructures of enclosed coolth are deeply structured into the ways in which cities are imagined, planned, and materialized, and distinctive forms of sociality have emerged in response. It is important to remember that the continued distribution of individual air-conditioned enclosures is largely considered an exercise of social responsibility, a type of caretaking. People need to be cooled, and air-conditioning performs this remedial function. However, this way of defining how we occupy our earthly home is fundamentally blind to the fact that we simultaneously contribute to its destruction. The next section examines the commons to imagine alternative infrastructures of care in a hot city.

\section{Commoning Coolth}

The commons concept is a powerful vehicle for troubling troubled times.

(Berlant, 2016, p. 395)

Increased urban heat is now troubling, and while one response is to shut our doors and close ourselves in a cocoon of thermal comfort, the price we pay is to still our bodies and close ourselves off from one another. Upon reviewing how technical cooling 
infrastructures have produced home as an enclosed and private space with a strong boundary that demarcates cool livability, we turn now to explore infrastructures that instate home as a space of flow and encounter across porous boundaries (Crabtree, 2006; Power, 2009), and that enact a commons that is continually in the making (Linebaugh, 2008). The commons referred to include cooling knowledge, practices, shared spaces, and built environments that are widely accessible for use in achieving thermal comfort, which also require care to be maintained and that produce benefit for a wide community (Gibson-Graham et al., 2013).

This commoning framework is applied in seeking a different understanding of the built environment, a redefinition of home that allows us to respond to heat in ways that are less energetically intensive, that incorporate common outdoor environments as part of our shared home environment (see Figure 1), and, following Brault (2017), pursue more social, convivial responses to a warming world. We want to harness the troubling power of the commons to expand our concept of home as a life-organizing infrastructure.

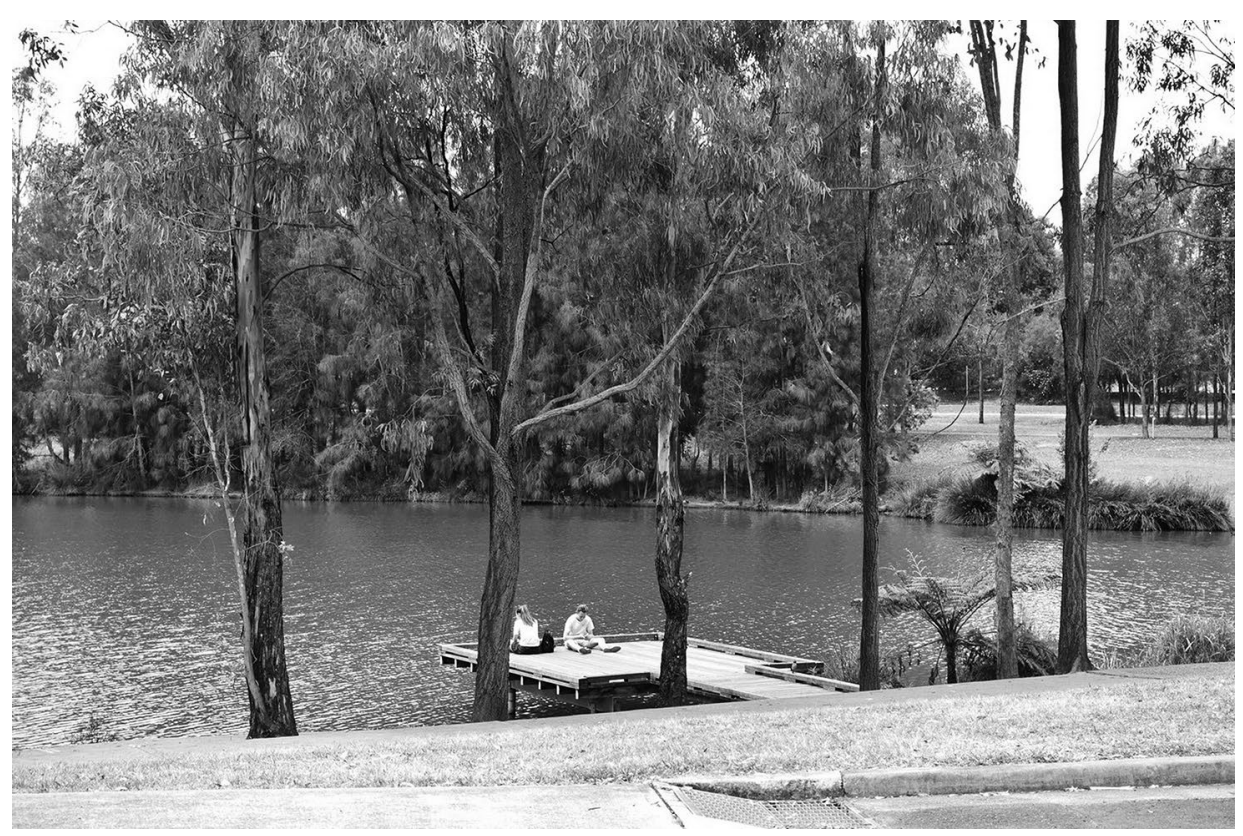

\section{Figure 1. Glenmore Loch, Glenmore Park: An oasis of coolth in one of Sydney's hottest suburbs.}

Source: Mellick Lopes et al. (2016, p. 13); photograph by Helen Amstrong, December 2015.

Participants in the Cooling the Commons study showed practices of commoned coolth have not completely disappeared. They did what they could to keep cool with the resources to which they had access in and around their homes, and where possible migrated to cool refuges such as pools, rivers, or shopping centers on extremely hot days. However, as air-conditioning has become a standard for the delivery of 
thermal comfort - each of those 180,000-plus new Western Sydney houses is highly likely to have air-conditioning - infrastructures that afford comfortable mobility in the broader public domain have fallen into decline and disrepair. This was clearly reflected in the experiences of the groups in this study. People perceived the removal of street trees, toilets, public drinking water facilities, and shaded seating over the years as a withdrawal of care that reinforced a deficit of trust in local government. ${ }^{7}$ This points to the critical relationship between interpersonal care and care of place. As discovered, traditional caregiving was constrained by structural features of the built environment-in homes, cars, and childcare centers. For the study participants, cared-for commons that provide for safe and comfortable mobility and invite participation existed primarily as memory or aspiration. Next, a summary of findings about residual, transgressive, and aspirational commons help inform our provisional guidelines in the following section.

\section{Keeping Common Knowledge Alive}

In spite of their restrictive environments, not all participants had lost common knowledge related to cooling. Older residents spoke of shared knowledge of ways to manipulate indoor environments to create coolth without air-conditioning. They demonstrated a high degree of practical know-how and sensitivity to environmental conditions, having developed a number of "work-arounds" for keeping cool in their often thermally poor houses using available materials and skills learned from their parents. They spoke of the importance of openable windows, ventilation, eaves, and verandas, the absence of which they had noticed in new housing developments, as well as an overall lack of interstitial "breathing space." Some had what Strengers and Maller (2017) called "practice memories" of very low-tech solutions, such as placing a baby under a table with a wet sheet over the top, or freezing water in cake tins and setting up a fan to blow air over it. This group was also adept at do-it-yourself modifications, such as installing heat-removing "whirlybirds" on their roofs.

\section{Caring for Residual Commons}

Participants shared many stories about cooling practices that circulated beyond the indoor environment, involving the distributed amenity of trees, rivers, and swimming pools, and more appropriately "furnished" public environments. People recalled sitting and swimming in rivers on hot days and public amenities that both assumed and supported a walkable city. They mentioned with disapproval the lack of nearby shaded green space, which has been associated with an increase in heat-related illness and death (Bradford et al., 2015). Of course, the perception of "nearby" changes according to how accessible such environments actually are. For parents in this study, the streets were generally perceived as too hot to push prams

7 These findings about features of the built environment constraining people's movement in a hot city resonate with and build on those reported in Sofoulis et al.'s (2008) study Out and About in Penrith of nearly a decade earlier. 
or walk, and paths were not pram friendly, broken up by roads. Seniors complained that there were few places to rest comfortably out and about: "The post office, myGov, and Centrelink; they feel like they are literally hundreds of miles apart" (Participants, seniors group). ${ }^{8}$

Participants were supportive of local council plans to reverse some of these trends and nurture the commons for wider participation. ${ }^{9}$ However, it is not a case of "build it and they will come." As Star (2010) argued, infrastructures both shape and are shaped by conventions of practice. Such strategies speak to a civic life that has been undernourished for some time. Normative social practices that have grown up around current conditions, such as children playing indoors for large parts of the day, will be difficult to change, and require multiple actions and interventions in relation to both built and social environments on an ongoing basis (Hunter et al., 2015).

\section{Tolerating Transgressive Commons}

Indoor shopping centers and fast-food restaurants are not only major sites of recreation in Western Sydney, but also cool places that can be accessed free of charge. During heat waves people in the region occupy these air-conditioned spaces for extended periods of time, transgressively commoning "privately" owned space. An important precedent study, Out and About in Penrith (Sofoulis et al., 2008), found that children identified play structures associated with the fastfood restaurants located inside shopping centers as the "park" (p. 39). This report concludes that such slippages of meaning are invited by the availability of both amenity (i.e., air-conditioning and toilets) and society in those environments, which are often not available in traditional outdoor parks. This delineates a further sociocultural context for the retreat indoors: a "conceptual infrastructure" (Berlant, 2016, p. 394) of the commons.

Among the groups, there was a sense of a right to occupy cool spaces in extreme circumstances. In another example of transgressive commoning, teenagers had resorted to swimming in the decorative water feature of an adjacent new housing development on hot days, as the local shuttle bus had been cancelled.

\section{Imagining Future Commons}

Another "emergent" commons was found in people's shared aspirations for the cool future city. These aspirations included the recovery of basic amenities that still existed strongly in memories of place. The provision of shade, shelter, and water in

\footnotetext{
8 The participants are referring to the shopfronts of government agencies that deliver social security payments and other social services to Australians.

9 For example, Parramatta City has new walkable city and bicycle plans, and in 2015 launched the Our Living River strategy, which is a plan to make at least some of Western Sydney's degraded rivers swimmable again by 2025.
} 
public environments was viewed as a necessary support to a far from basic range of social affordances, including meeting and gathering, resting and waiting, swimming, walking, and the everyday exchange of knowledge and ideas. However, participants went beyond this to describe multipurpose environments, such as parking lots or roads, that could be used for different activities at different times of the day, and called for a more extensive use of the rivers and riverside parks. They also imagined alternative social futures: the seniors were keen to share their cooling expertise with others, and the gardeners across the groups were interested in sharing knowledge about on-site water management, as well as supporting conversations about trees and their social, cultural, and environmental significance. Community cooking was also an aspiration in the groups, a way to share knowledge and enjoy social interaction in a local setting. It was noted that this would require access to material infrastructures beyond the currently ubiquitous local park barbecue.

These commoning practices foreshadow a future home space that goes well beyond the individualized enclosures currently on offer as "home," and the ontologies they produce. The technical infrastructures of coolth that both assume and produce a passive and static body (whether that body is positioned inside or outside an air-conditioned cocoon) chip away at the capacity for civic life. Conversely, the infrastructures we seek to promote are both social and technical, requiring a multiplicity of resources distributed across and between private and public domains. In the following section, our learning from the Cooling the Commons project supports the generation of a preliminary set of considerations for designing infrastructures of care.

\section{Designing Infrastructures of Care}

[A]t some crisis times like this one, politics is defined by a collectively held sense that a glitch has appeared in the reproduction of life. A glitch is an interruption within a transition, a troubled transmission. A glitch is also the revelation of an infrastructural failure. (Berlant, 2016, p. 393)

As climate change threatens the reproduction of life, infrastructures of thermal comfort through enclosure are exposed as failing to care for people and the planet. The time is ripe to mount a challenge to these infrastructures and the embodied and public geographies of thermal restriction they support. Care is a world-making practice (Slater, 2016), as is design (Fry, 1999). The ability of designed artifacts and systems to alter the condition and behavior of other things in multiple incremental ways constitutes the ethical force of design. Elaine Scarry (1985) described this force as an empathetic projection through which the designer says to another, "in ... this small way, be well" (p. 292). In the context of this study, the question becomes what lifeworlds are being cared for, and what diminished or undermined, by design? 
We have seen how heat reaches into people's lives in different ways, depending on their physical, material, socioeconomic, and even cultural circumstances. In the context of rising heat, city inhabitants need different ways to be at home beyond the skin of an enclosed, private domain. This requires a far more convivial sociomaterial environment that precedes artificial air, rather than assumes it.

The last section of this paper explores the possibilities for infrastructures of sociality and circulation, which enable communities to be at home in places where "the body multiple" can find expression. Enumerated here are some key considerations for a careful design practice that could support future homes as a care commons and that recognizes the significance of design in the patterning of sociomaterial relationships. Important to note are that attempts to design in another way are constrained by the modern city, as it is largely a heat-amplifying hot zone. As Tonkinwise (2009) argued, what is now required is not a more systemic form of designing, but one that performs "a plurality of more humble, agile propositions that allow for the evolution of less ecologically harmful ways of keeping cool” (p. 37).

\section{Open and Porous Infrastructures of the Commons}

People need designed commons that are accessible and appropriately furnished with amenities and "attractors." A significant challenge here is negotiating the terms of ownership and not necessarily "giving in" to the neoliberal narrative of exclusivity, in that every home has every thing and spare capacity is ignored.

There is a need to consider how to support the acclimatization to more open and porous infrastructures of the commons, including their sensorial dimensions. For example, if one cooks out in the open, along with food they will be sharing smells and sounds with their neighbors. Therefore, in addition to the infrastructures for community cooking, might be the need for new protocols to govern how social spaces are shared. These would want to be anticipated in advance rather than reactively, as part of a more careful design ethos. ${ }^{10}$

\section{Distributing Spare Cool Capacity}

How might spare cool capacity-created in part by the settings of thermal indulgence and monotony in autonomous, air-conditioned environments-be better shared? This is of particular importance, as single-occupant dwellings are on the rise in Australia, with one in every four being a lone household, skewed to older age groups (ABS, 2018b). Older people are not only deemed more at risk of heat-

10 There are numerous examples of a lack of anticipatory care in design decision-making related to transient usage. The intrusive effect of light spill from sportsfield floodlights on human and nonhuman residents is but one obvious case in point. 
related illnesses than younger people, but are also at risk of social isolation; hence, this trend is significant in terms of home rethought as a sociothermal infrastructure of care (Power \& Mee, in press).

\section{Sharing Cooling Centers}

In Pittsburgh, Pennsylvania, public buildings in areas of high vulnerability have been reconceived as cooling centers where at-risk residents can seek refuge from extreme heat. The optimal location for cooling centers was identified through the use of a "heat vulnerability index" (Bradford et al., 2015). This research notes that the repurposing of existing buildings may be preferable to purpose-built "cooling centers," as people may not wish to be labeled as "vulnerable" and in need of special facilities. For a rapidly developing but dispersed geospatial context like Western Sydney, a "patchwork" approach to the provision of artificially cooled air would build on social practices that transgress existing environments and could facilitate the development of new social networks. This suggests the need for a shift in focus from the design of individually enclosed and autonomous dwellings to shared infrastructures such as libraries, hospitals, schools, childcare centers, swimming pools, and community centers, among others, which are open to the circulation of air and people, as well as to multipurpose use. A careful consideration of how these infrastructures might be freely accessed during extreme heat events implies that contextual sensitivity should be part of their design. Such material infrastructures also require social response plans designed by the communities who will inhabit them, so that, for example, vulnerable families or lone residents might be identified and their care anticipated. Arguably, this sort of participatory care planning should form part of the induction of people into any new community.

\section{Participating in Planning, Repairing, and Maintaining Infrastructures of Care}

Commons designed to make space for people to make their mark and contribute their own practical knowledge and skills are a necessity. Reflecting on those keen gardeners in the Cooling the Commons study, a key example here would be a community garden, which can be understood as an "enabling platform" (Jégou \& Manzini, 2008) to reduce radiant heat effects, support ecological literacies, and facilitate learning communities (Mellick Lopes \& Shumack, 2012). The garden is a living design that calls for time and attention but gives back in the form of food, habitat, and social learning: a knowledge commons.

In response to the effect of declining infrastructures that are vital to sustain the comfortable mobility of people in a hot city, equally necessary are designed environments that are repairable and maintainable, and that invite the participation of residents. Design that has internalized the normality of air-conditioning has 
to relearn the importance of basic "passive design" features such as appropriate orientation, shading, ventilation, and weatherization, but their effective use requires human occupants to become more sensitive, anticipating changes in temperature throughout the day, and more engaged in actively controlling indoor climate.

Stewart Brand (1994) argued that modern designed homes prioritize the "show surface" and do not tend to invite ongoing maintenance and care- thus, the need for incremental maintenance and care is forgotten, leading on occasion to catastrophic failure. The technical delegation of care to air-conditioning further exacerbates the decline of a "maintaining eye" and a skilled hand. Designed environments that not only allow for people to manipulate them, but also to practice their care of and investment in them, require commoning infrastructures such as shared tools, spaces, and knowledge.

\section{Performing Preparation for Extreme Heat}

Finally, people need support to become care commoners, such as forms of induction and instruction, which can help facilitate the performance of unfamiliar social and technical practices, including the management and maintenance of commons.

One important form of induction in relation to extreme heat is a community weather preparedness plan. Most are familiar with strategies to prepare for flood and fire, but equally needed are plans to prepare for extreme weather. Rather than generic measures and checklists designed to help individual households fend for themselves, a community preparedness plan would require people to assess where the vulnerable members of their community are, where the spare cool capacity is, and plan to bring them together on hot days. This might involve the design of a purposive social network that is activated on the basis of certain indicators such as weather forecasts. An important precedent here is Akama et al.'s (2014) work on bushfire preparedness - the researchers worked with communities to identify and visualize social bonds, bridges, and links to help people think like a community with a common concern during times of emergency. Such an approach makes an important contribution to supporting the adaptive capacity of communities living in extreme conditions (Akama et al., 2014).

\section{Conclusion}

The commons is an action concept that acknowledges a broken world and the survival ethics of a transformational infrastructure. (Berlant, 2016, p. 399)

The sobering reality that we confront is an Australia where 50-degree $\left(122^{\circ} \mathrm{F}\right)$ summer days may become a normal event in Sydney by 2040, sooner in other metropolitan areas, even if the international community abides by the terms of the 2015 Paris 
Agreement (Lewis et al., 2017). Certainly, air-conditioned environments will have to be one response to a much warmer world, but, arguably, the equitable distribution of coolth will have to accompany adaptive responses. As we move toward these futures of designed circulation, there is a need to develop the infrastructures and practices of sociality that can sustain them. The Cooling the Commons participants remind us that this is a process of the generational circulation of ideas and practice, in which historical and new knowledge and practices must continue to cross-fertilize to imagine new practices of urban habitation.

The Cooling the Commons study was an initial exploration of sociomaterial responses to the complex and dynamic problem of urban heat in a specified geographic location. As a transdisciplinary team of researchers, we seek to further expand and test some of the preliminary design considerations emerging from that study in a research program that aims to actively "improve the situation of inquiry" (Mitchell et al., 2016). This requires the development of integrated concepts that can translate the memories, improvisational transgressions, and aspirations we identified in Cooling the Commons into an approach to design apprehensible to policy-makers, planners, and developers alike. For this we need to perform engaged research that is, from the outset, change-oriented, and that works with, and cares for, commons infrastructure. Concurrently, we seek to challenge the practices that are constitutive of ever hotter urban futures; while good design may ameliorate the worst effects of the heat without compromising our sociality, bad design — that is, more impermeable heat-absorbing surfaces, energy-demanding buildings, and isolating structureswill serve to make the problems worse.

The multiple design interventions we propose, rather than simply reducing home to house-as-enclosure, instead seek to reimagine the home as a porous and socially connected space tied to other spaces that enhance community preparedness in the face of a much warmer Australia. Following De Angelis and Harvie (2013), we see the prospects for the cool commons as a break in the historic trajectory of thermal enclosure. Pursuing this alternative makes new demands upon us as researchers, our fellow citizens, and decision-makers. We hope it is clear that we do not propose that designed recalibrations of the material environment in themselves constitute a cool commons. As anthropologist Stephen Gudeman (2001) reminded us many years ago, the commons do not exist without a community that both uses and cares for it.

\section{Acknowledgments}

The authors would like to acknowledge the contributions of Helen Armstrong and Cameron Tonkinwise in developing our Cooling the Commons research agenda. Helen Armstrong was also a key researcher on the Cooling the Commons pilot study. 


\section{References}

Akama, Y., Chaplin, S., \& Fairbrother, P. (2014). Role of social networks in community preparedness for bushfire. International Journal of Disaster Resilience in the Built Environment, 5(3), 277-291. doi.org/10.1108/IJDRBE-01-2014-0010

Amati, M., Boruff, B., Caccetta, P., Devereux, D., Kaspar, J. Phelan, K., \& Saunders, A. (2017). Where should all the trees go? Investigating the impact of tree canopy cover on socioeconomic status and wellbeing in LGA's. Prepared for Horticulture Innovation Australia by the Centre for Urban Research. Melbourne, VIC: RMIT University. Retrieved from www.urbanaffairs.com.au/downloads/2017-9-28-2.pdf

Australian Bureau of Statistics. (2018a). Census of population and housing: Socio-economic indexes for areas (SEIFA), Australia, 2016 (Catalogue No. 2033.0.55.001). Retrieved from www.abs.gov.au/ausstats/abs@.nsf/mf/2033.0.55.001

Australian Bureau of Statistics. (2018b). Census of population and housing: Stories from the census, 2016 (Catalogue No. 2071.0). Retrieved from www.abs.gov.au/ausstats/abs@. $\mathrm{nsf} / \mathrm{mf} / 2071.0$

Bell, S. L., Phoenix, C., Lovell, R., \& Wheelier, B. (2014). Green space, health and wellbeing: Making space for individual agency. Health \& Place, 30, 287-292. doi.org/0.1016/ j.healthplace.2014.10.005

Berlant, L. (2016). The commons: Infrastructure for troubling times. Environment and Planning D: Society and Space, 34(3), 393-419. doi.org/10.1177/0263775816645989

Bradford, K., Abrahams, L., Hegglin, M., \& Klima, K. (2015). A heat vulnerability index and adaptation solutions for Pittsburgh, Pennsylvania. Environmental Science and Technology, 49(19), 11303-11311. doi.org/10.1021/acs.est.5b03127

Brand, S. (1994). How buildings learn: What happens after they're built. New York, NY: Penguin Books.

Brault, C. (2017). Feminist imaginations in a heated climate: Parody, idiocy, and climatological possibilities. Catalyst: Feminism, Theory, Technoscience, 3(2), 1-33. doi.org/ $10.28968 /$ cftt.v3i2.28847

Crabtree, L. (2006). Disintegrated houses: Exploring ecofeminist housing and urban design options. Antipode, 38(4), 711-734. doi.org/10.1111/j.1467-8330.2006.00473.x

Davis, L. W., \& Gertler, P. J. (2015). Contribution of air conditioning adoption to future energy use under global warming. Proceedings of the National Academy of Sciences of the United States of America, 112(9), 5962-5967. doi.org/10.1073/pnas.1423558112

De Angelis, M., \& Harvie, D. (2013). The commons. In M. Parker, G. Cheney, V. Fournier, \& C. Land (Eds.), The Routledge companion to alternative organisation (pp. 280-294). London, UK: Routledge. 
De la Rue du Can, S., Leventis, G., \& Shah, N. (2015). Lessons learned from incentive programs for efficient air conditioners: A review (Research Report). Berkeley, CA: Lawrence Berkeley National Laboratory. Retrieved from archive.cleanenergyministerial.org/Portals/2/pdfs/ SEAD_Incentive_Programs_Efficient_ACs.pdf

Fry, T. (1999). A new design philosophy: An introduction to defuturing. Sydney, NSW: UNSW Press.

Gibson-Graham, J. K., Cameron, J., \& Healy, S. (2013). Take back the economy: An ethical guide for transforming our communities. Minneapolis, MN: University of Minnesota Press.

Greater Sydney Commission. (2018). Western city district plan. Retrieved from www.greater. sydney/western-city-district-plan

Gudeman, S. (2001). The anthropology of economy: Community, market, and culture. Malden, MA \& Oxford, UK: Blackwell Publishers.

Hayden, D. (2002). Redesigning the American dream: The future of housing, work and family life (2nd ed.). New York, NY \& London, UK: W. W. Norton.

Healy, S. (2008). Air-conditioning and the "homogenization" of people and built environments. Building Research \& Information, 36(4), 312-322. doi.org/10.1080/ 09613210802076351

Hughes, L., Hanna, E., \& Fenwick, J. (2016). The silent killer: Climate change and the health impacts of extreme heat. Sydney, NSW: Climate Council of Australia.

Hunter, R. F., Christian, H., Veitch, J., Astell-Burt, T., Hipp, J. A., \& Schipperjin, J. (2015). The impact of interventions to promote physical activity in urban green space: A systematic review and recommendations for future research. Social Science \& Medicine, 124, 246-256. doi.org/10.1016/j.socscimed.2014.11.051

Jacobs, B., Mikhailovich, N., \& Delaney, C. (2014). Benchmarking Australia's urban tree canopy: An i-Tree assessment. Prepared for Horticulture Australia Limited by the Institute for Sustainable Futures. Sydney, NSW: University of Technology Sydney. Retrieved from 202020vision.com.au/media/7141/benchmarking_australias_urban_tree_canopy.pdf

Jégou, F., \& Manzini, E. (2008). Collaborative services: Social innovation and design for sustainability. Milan, Italy: Edizioni POLI.design.

Klepeis, N. E., Nelson, W. C., Ott, W. R., Robinson, J. P., Tsang, A. M., \& Switzer, P., ... Engelmann, W. H. (2001). The National Human Activity Pattern Survey (NHAPS): A resource for assessing exposure to environmental pollutants. Journal of Exposure Analysis and Environmental Epidemiology, 11(3), 231-252. doi.org/10.1038/sj.jea.7500165

Lewis, S. C., King, A. D., \& Mitchell, D. M. (2017). Australia's unprecedented future temperature extremes under Paris limits to warming. Geophysical Research Letters, 44(19), 9947-9956. doi.org/10.1002/2017GL074612

Linebaugh, P. (2008). The Magna Carta manifesto: Liberties and commons for all. Berkeley, CA: University of California Press. 
Loughnan, M. E., Tapper, N. J., Phan, T., Lynch, K., \& McInnes, J. A. (2013). A spatial vulnerability analysis of urban populations during extreme heat events in Australian capital cities. Gold Coast, QLD: National Climate Change Adaptation Research Facility. Retrieved from www.nccarf.edu.au/business/sites/www.nccarf.edu.au.business/files/ attached_files_publications/Loughnan-ExtremeHeatEventsinAustralianCapitalCitiesHighRes.pdf

Mellick Lopes, A., Gibson, K., Crabtree, L., \& Armstrong, H. (2016). Cooling the commons (Pilot Research Report). Penrith, NSW: Western Sydney University. Retrieved from www. westernsydney.edu.au/_data/assets/pdf_file/0020/1161470/cooling-the-commonsreport.pdf

Mellick Lopes, A., \& Shumack, K. (2012). "Please ask us": Conversation mapping as design research: Social learning in a verge garden site. Design Philosophy Papers, 10(2), 119-132. doi.org/10.2752/089279312X13968781797832

Mitchell, C., Cordell, D., \& Fam, D. (2016). Beginning at the end: The outcome spaces framework to guide purposive transdisciplinary research. In D. Fam, J. Palmer, C. Riedy, \& C. Mitchell (Eds.), Transdisciplinary research and practice for sustainability outcomes (pp. 25-38). London, UK: Routledge.

Mol, A. (1999). Ontological politics. A word and some questions. The Sociological Review, 47(Suppl 1), 74-89. doi.org/10.1111/j.1467-954X.1999.tb03483.x

Mol, A. (2002). The body multiple: Ontology in medical practice. Durham, NC: Duke University Press.

Mol, A. (2008). The logic of care: Health and the problem of patient choice. London, UK: Routledge.

Nicholls, L., McCann, H., Strengers, Y., \& Bosomworth, K. (2017). Heatwaves, homes \& health: Why household vulnerability to extreme heat is an electricity policy issue. Melbourne, VIC: Centre for Urban Research, RMIT University. Retrieved from cur.org.au/cms/wpcontent/uploads/2017/11/heatwaves-homes-and-health-rmit_full-report.pdf

Osmond, P., \& Sharifi, E. (2017). Guide to urban cooling strategies. Low Carbon Living CRC. Retrieved from www.lowcarbonlivingcrc.com.au/resources/crc-publications/ crclcl-project-reports/guide-urban-cooling-strategies-2017

Penrith City Council. (2015). Cooling the city strategy. Retrieved from www.penrithcity.nsw. gov.au/Waste-and-Environment/Sustainability/Beat-the-heat---Cooling-the-City/

Polanyi, M. (2009). The tacit dimension. Chicago, IL: University of Chicago Press.

Power, E. R. (2009). Border-processes and homemaking: Encounters with possums in suburban Australian homes. Cultural Geographies, 16(1), 29-54. doi.org/10.1177/147 4474008097979

Power, E. R., \& Mee, K. J. (in press). Housing as an infrastructure of care. 
SafeWork NSW. (n.d.). Maintaining thermal comfort in indoor work environments. Retrieved from www.safework.nsw.gov.au/resource-library/heat-and-environment/maintainingthermal-comfort-in-indoor-work-environments

Scarry, E. (1985). The body in pain: The making and unmaking of the world. New York, NY: Oxford University Press.

Schwarz, K., Fragkias, M., Boone, C. G., Zhou, W., McHale, M., Grove, J. M., ... Cadenasso, M. L. (2015). Trees grow on money: Urban tree canopy cover and environmental justice. PLoS ONE, 10(4), e0122051. doi.org/10.1371/journal.pone.0122051

Shove, E. (2003). Comfort, cleanliness and convenience: The social organization of normality. Oxford, UK \& New York, NY: Berg.

Slater, L. (2016). Questioning care. In A. Hickey (Ed.), The pedagogies of cultural studies (1st ed., pp. 119-132). New York, NY: Routledge.

Sofia (Sofoulis), Z. (2000). Container technologies. Hypatia, 15(2), 181-201. doi.org/ 10.1111/j.1527-2001.2000.tb00322.x

Sofoulis, Z., Armstrong, H., Bounds, M., Mellick Lopes, A., \& Andrews, T. (2008). Out and about in Penrith: Universal design and cultural context: Accessibility, diversity and recreational space in Penrith: Final report. Penrith, NSW: University of Western Sydney. Retrieved from www.uws.edu.au/_data/assets/pdf_file/0008/46367/Out_and_About _Final_Report_with_Appendices.pdf

Star, S. L. (2010). This is not a boundary object: Reflections on the origin of a concept. Science, Technology, \& Human Values, 35(5), 601-617. doi.org/10.1177/0162243910377624

Strengers, Y., \& Maller, C. (2017). Adapting to "extreme" weather: Mobile practice memories of keeping warm and cool as a climate change adaptation strategy. Environment and Planning A: Economy and Space, 49(6), 1432-1450. doi.org/10.1177/0308518X1769 4029

Tonkinwise, C. (2009). Weeding the city of unsustainable cooling, or, many designs rather than massive design. In L. Tilder \& B. Blostein (Eds.), Design ecologies: Essays on the nature of design (pp. 26-39). New York, NY: Princeton Architectural Press. 
This text is taken from Human Ecology Review, Volume 24, Number 2, 2018, published by ANU Press, The Australian National University, Canberra, Australia. doi.org/10.22459/HER.24.02.2018.03 